\title{
Aortic valve surgery: Marked increases in volume and significant decreases in mechanical valve use — an analysis of 41,227 patients over 5 years from the Society for Cardiothoracic Surgery in Great Britain and Ireland National database
}

\author{
Joel Dunning, PhD, ${ }^{\mathrm{a}}$ Haiyan Gao, PhD,${ }^{\mathrm{b}}$ John Chambers, MD, FRCP, ${ }^{\mathrm{c}}$ Neil Moat, MS, FRCS, ${ }^{\mathrm{d}}$ \\ Gavin Murphy, MD, ${ }^{\mathrm{e}}$ Domenic Pagano, MD, FRCS(CTh),${ }^{\mathrm{f}}$ Simon Ray, MD, FRCP, ${ }^{\mathrm{g}}$

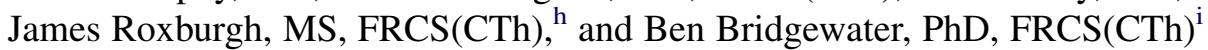

\begin{abstract}
Objectives: Aortic valve replacement is accepted as a standard treatment for aortic stenosis and regurgitation. To help plan the national requirement for conventional and catheter-based procedures, we have analyzed the Society for Cardiothoracic Surgery in Great Britain and Ireland audit database to look at changes in practice over time.
\end{abstract}

\begin{abstract}
Methods: All patients undergoing conventional aortic valve replacement with or without coronary artery surgery from April 2004 to March 2009 were included. The main outcome measures were changes in the number, characteristics, operative details, and in-hospital mortality. We have looked particularly at trends and outcomes in elderly and high-risk patients (EuroSCORE of 10 or more) who may now be considered for percutaneous aortic valve insertion.
\end{abstract}

Results: A total of 41,227 patients underwent aortic valve surgery over 5 years with an in-hospital mortality of $4.1 \%$. The annual number increased from 7396 in 2004-2005 to 9333 in 2008-2009, with significant increases $(P<.0005)$ in mean age $(68.8-70.2$ years $)$, the proportion of patients with aortic stenosis $(62.4 \%-65.1 \%)$, octogenarians $(13.6 \%-18.4 \%)$, high-risk patients $(24.6 \%-27.7 \%)$, and those receiving biological valves $(65.4 \%$ $77.8 \%$ ). The incidence of permanent cerebrovascular accident was $1.2 \%$ and $1.0 \%$ in patients having only an aortic valve replacement. The dialysis rate was $4.5 \%$ and the reoperation rate for bleeding was $6.6 \%$. Overall mortality decreased from $4.4 \%$ in $2004-2005$ to $3.7 \%$ in $2008-2009$. Survival to a mean follow-up of 2.5 years was $89 \%$.

Conclusions: We have seen a large increase in annual volume of aortic valve replacements, with more patients undergoing surgery for aortic stenosis and an increase in surgery in the elderly and high-risk patients. (J Thorac Cardiovasc Surg 2011;142:776-82)

$\mathcal{B}$ Supplemental material is available online.

\footnotetext{
From the Department of Cardiothoracic Surgery, ${ }^{a}$ James Cook University Hospital, Middlesbrough, United Kingdom; the National Institute for Clinical Outcomes Research, ${ }^{\mathrm{b}}$ University College, London, United Kingdom; Department of Cardiology, ${ }^{\mathrm{C}}$ Guys and Thomas' Hospital, London, United Kingdom; the Department of Cardiothoracic Surgery, ${ }^{\mathrm{d}}$ Royal Brompton Hospital, United Kingdom; the Department of Cardiothoracic Surgery, ${ }^{\mathrm{e}}$ Bristol Royal Infirmary, United Kingdom; the Department of Cardiothoracic Surgery, ${ }^{\mathrm{f}}$ Queen Elizabeth University Hospital, Birmingham, United Kingdom; the Department of Cardiology, ${ }^{\mathrm{g}}$ University Hospital of South Manchester, United Kingdom; the Department of Cardiothoracic Surgery, St Thomas' Hospital, London, United Kingdom; and the Department of Cardiothoracic Surgery, ${ }^{\mathrm{i}}$ Manchester Academic Health Science Centre, University Hospital of South Manchester, Manchester, United Kingdom.

Disclosures: Authors have nothing to disclose with regard to commercial support.

Received for publication Jan 12, 2011; revisions received March 31, 2011; accepted for publication April 15, 2011.

Address for reprints: Ben Bridgewater, PhD, FRCS(CTh), Honorary Reader, Manchester Academic Health Science Centre, University Hospital of South Manchester, Southmoor Road Manchester, M23 9LT, United Kingdom (E-mail: ben. bridgewater@uhsm.nhs.uk).

$0022-5223 / \$ 36.00$

Copyright $(\odot 2011$ by The American Association for Thoracic Surgery doi:10.1016/j.jtcvs.2011.04.048
}

Aortic valve replacement (AVR) is a class I indication for surgery for patients with symptomatic severe aortic stenosis or regurgitation. ${ }^{1}$ Successful surgery improves both symptoms and life expectancy in these patients. Recently, there have been several developments; there are increasing reports about the longevity of biological valves, and novel treatments of aortic valve disease via catheter-based or transapical approaches are being introduced for high-risk patients. ${ }^{2,3}$ Planning transcatheter aortic valve intervention services nationally requires information about the numbers of suitable patients. If conventional surgery is becoming safer, the need for transcatheter aortic valve intervention is less clear. Therefore, to study changes in practice over time and establish clear contemporary outcomes after conventional aortic valve surgery to help inform decision making for high-risk patients, we have analyzed a large national database.

\section{PATIENTS AND METHODS}

Since 1994 the Society for Cardiothoracic Surgery of Great Britain and Ireland has been involved with a Central Cardiac Audit database project to 


\section{Abbreviations and Acronyms}

AVR = aortic valve replacement

$\mathrm{CABG}=$ coronary artery bypass grafting

CI = confidence interval

NYHA $=$ New York Heart Association

STS $=$ Society of Thoracic Surgeons

which cardiac surgical units submit online encrypted data including preoperative patient characteristics, operative details, and postoperative outcomes (www.ccad.org.uk). Survival data come from the Office of National Statistics. We have analyzed these data for the 5-year time period from April 1, 2004, to March 31, 2009.

We have extracted all patients undergoing aortic valve surgery including those undergoing concomitant coronary artery bypass grafting (CABG). We have excluded patients undergoing other concomitant aortic procedures including those having a procedure for atrial fibrillation. Patients aged less than 18 years of age were also excluded.

We have defined high-risk patients as those with a logistic EuroSCORE ${ }^{4}$ of 10 or more. We have looked at the overall incidence, influence on inhospital mortality, and changes over time of the following preoperative and operative risk factors: sex, age, symptom status (New York Heart Association [NYHA] class), diabetes, operative priority, left ventricular function, renal function, previous cardiac surgery, chronic obstructive pulmonary disease, peripheral vascular disease, atrial fibrillation/flutter, concomitant coronary artery surgery, cardiogenic shock, and body mass index. In-hospital mortality was defined as any death occurring in hospital during the same admission. We have looked at the independent predictors of the in-hospital mortality in this group using logistic regression.

\section{Statistical Analysis}

Age is presented as a mean with standard deviation, with 1-way analysis of variance used to test the differences or trend as appropriate. Categorical variables are presented as frequencies and percentages. The $\chi^{2}$ test was used to assess the associations between the categorical variables unless the variable was dichotomous, in which case Fisher's exact test was used. The $\chi^{2}$ test for trend (linear-by-linear association test) was used to assess variable trends. Multivariate logistic regression was used to identify independent risk factors for in-hospital mortality. Candidate variables with a $P$ value less than .1 were entered into the regression model. Statistical analyses were performed with SPSS version 18.0 (SPSS, Inc, Chicago, Ill).

\section{RESULTS}

\section{Change in Numbers Undergoing AVR and Inpatient Characteristics}

A total of 41,227 patients underwent aortic valve surgery during the time period of study. Over the 5 years there was an increase in the number of patients undergoing aortic valve surgery each year from 7396 in 2004-2005 to 9333 in $2008-2009$, with a small but statistically significant increase in mean age from 68.8 to 70.2 years old $(P<.0005)$ (Table 1). There were significant increases (all $P<.0005$ ) in the proportion of patients with aortic stenosis $(62.4 \%-65.1 \%)$, octogenarians $(13.6 \%-18.4 \%)$, and high-risk patients (24.6\%-27.7\%) There was no significant change in the proportion of patients undergoing concomitant CABG.

\section{In-Hospital Mortality and the Univariate Associations With Mortality}

The overall in-hospital mortality was $1700(4.1 \%)$ (Table 2). The mortality for those over the age of 80 was $452(8.1 \%)$ and for patients 85 or older $131(8.1 \%)$. For patients with a logistic EuroSCORE of 10 or more, the mortality was $1042(9.5 \%)$. Over the 5 years there was a small but statistically significant decrease in the overall mortality from $4.4 \%$ in $2004-2005$ to $3.7 \%$ in $2008-2009$, with significant decreases for patients with a logistic EuroSCORE of 10 or more $(10.8 \%-8.8 \% ; P=.032)$ and those receiving biological valves $(5.1 \%-4.0 \% ; P=.008)$. The incidences of various risk factors and the univariate association with in-hospital mortality for all patients are shown in Table 3 . The statistically significant risk factors include age of 80 years or more, female gender, low ejection fraction, NYHA class III/IV, Canadian Cardiovascular Surgery class III/IV, previous cardiac surgery, diabetes, peripheral vascular disease, nonelective surgery, renal function, chronic obstructive pulmonary disease, absence of sinus rhythm, concomitant coronary artery surgery, valve implant type, body mass index, and cardiogenic shock.

\section{Ratio of Biological to Mechanical Valves}

The proportion of patients receiving biological valves increased significantly through the study period from $65.4 \%$ in 2004-2005 to $77.8 \%$ in 2008-2009 (Table 4). There were increases in the proportion of biological valves inserted in all age groups. For patients over 70 years of age the percentage increased from $87 \%$ in $2004-2005$ to $95 \%$ in 2008 2009 , whereas for those under 55 the percentage increased from $18 \%$ in $2004-2005$ to $25 \%$ in $2008-2009$.

\section{Comparison of Patients Undergoing Isolated AVR and AVR Plus CABG}

A total of 16,684 patients underwent combined AVR and grafts, and 24,543 patients underwent isolated AVR (Table 5 ). The patients undergoing combined surgery were significantly older (mean age 73.0 vs 66.9 years; $P<.0005$ ), with a higher proportion (all $P<.0005)$ of octogenarians $(20.0 \%$ vs $13.1 \%$ ), high-risk patients $(48.2 \%$ vs $23.3 \%)$, patients with aortic stenosis $(69.5 \%$ vs $59.8 \%)$, and those receiving biological valves ( $82.4 \%$ vs $67.0 \%)$, and with a significantly lower proportion $(P<.0005)$ of women $(29.6 \%$ vs $43.0 \%)$ and those receiving mechanical valves $(17.3 \%$ vs $32.0 \%)$.

In terms of other comorbidities, the incidence of permanent cerebrovascular accident in all 41,227 was $1.2 \%$. In patients who had AVR only the incidence of cerebrovascular accident was $1.0 \%$. The incidence of dialysis among all patients was $4.5 \%$ and $3.6 \%$ in patients receiving only an AVR. The total reoperation rate for bleeding was $6.6 \%$ and the reoperation rate for any reason was $8.2 \%$ (Table E1). 
TABLE 1. Changes in patient demographics over time

\begin{tabular}{|c|c|c|c|c|c|c|c|}
\hline & \multicolumn{6}{|c|}{ Financial year } & \multirow{2}{*}{$\begin{array}{l}P \text { value } \\
\text { for trend }\end{array}$} \\
\hline & Total & 2004-2005 & 2005-2006 & 2006-2007 & 2007-2008 & 2008-2009 & \\
\hline No. of patients & 41,227 & 7,396 & 7,816 & 8,097 & 8,585 & 9,333 & \\
\hline Age (y), mean (SD) & $69.3(11.8)$ & $68.8(11.8)$ & $68.8(11.8)$ & $69.4(11.6)$ & $69.5(12.0)$ & $70.2(11.6)$ & $<.0005$ \\
\hline Female gender, $\mathrm{n}$ (row \%) & $15,495(37.6 \%)$ & $2800(37.9 \%)$ & $2925(37.4 \%)$ & $3022(37.3 \%)$ & $3203(37.3 \%)$ & $3545(38.0 \%)$ & .874 \\
\hline BMI, n (row \%) & $27.8(5.06)$ & $27.4(4.90)$ & $27.6(5.04)$ & $27.7(4.97)$ & $27.9(5.15)$ & $28.1(5.05)$ & $<.0005$ \\
\hline Impaired LV, n (row \%) & $12,207(29.6 \%)$ & $2234(30.2 \%)$ & $2319(29.7 \%)$ & $2447(30.2 \%)$ & $2552(29.7 \%)$ & $2655(28.4 \%)$ & .022 \\
\hline NYHA III-IV, n (row \%) & $18,934(45.9 \%)$ & $3565(48.2 \%)$ & $3562(45.6 \%)$ & $3707(45.8 \%)$ & $3927(45.7 \%)$ & $4173(44.7 \%)$ & $<.0005$ \\
\hline Presence of diabetes, $\mathrm{n}$ (row \%) & $6538(15.9 \%)$ & $1022(13.8 \%)$ & $1144(14.6 \%)$ & $1277(15.8 \%)$ & $1479(17.2 \%)$ & $1616(17.3 \%)$ & $<.0005$ \\
\hline $\begin{array}{l}\text { Previous cardiac surgery, } \\
\text { n (row } \%)\end{array}$ & $3530(8.6 \%)$ & $662(9.0 \%)$ & $672(8.6 \%)$ & $722(8.9 \%)$ & $701(8.2 \%)$ & $773(8.3 \%)$ & .069 \\
\hline Nonelective, n (row \%) & $10,282(24.9 \%)$ & $1891(25.6 \%)$ & $2024(25.9 \%)$ & $2073(25.6 \%)$ & $2208(25.7 \%)$ & $2086(22.4 \%)$ & $<.0005$ \\
\hline Octogenarians, n (row \%) & $6563(15.9 \%)$ & $1007(13.6 \%)$ & $1095(14.0 \%)$ & $1308(16.2 \%)$ & $1433(16.7 \%)$ & $1720(18.4 \%)$ & $<.0005$ \\
\hline $\begin{array}{l}\text { Extracardiac arteriopathy, } \\
\text { n (row \%) }\end{array}$ & $4306(10.5 \%)$ & $713(9.8 \%)$ & $806(10.4 \%)$ & $814(10.1 \%)$ & $900(10.5 \%)$ & $1073(11.6 \%)$ & $<.0005$ \\
\hline $\begin{array}{l}\text { Absence of sinus rhythm, } \\
\text { n (row \%) }\end{array}$ & $6008(14.6 \%)$ & $1023(13.8 \%)$ & $1098(14.0 \%)$ & $1181(14.6 \%)$ & $1299(15.1 \%)$ & $1407(15.1 \%)$ & .004 \\
\hline Renal impairment, n (row\%) & $1515(3.7 \%)$ & $296(4.0 \%)$ & $284(3.6 \%)$ & $290(3.6 \%)$ & $328(3.8 \%)$ & $317(3.4 \%)$ & .118 \\
\hline Pulmonary disease, $n$ (row\%) & $6193(15.0 \%)$ & $1054(14.3 \%)$ & $1265(16.2 \%)$ & $1214(15.0 \%)$ & $1244(14.5 \%)$ & $1416(15.2 \%)$ & .957 \\
\hline $\begin{array}{l}\text { High risk }(\text { EuroSCORE }>10) \\
\text { n }(\text { row } \%)\end{array}$ & $11,043(26.8 \%)$ & $1816(24.6 \%)$ & $2060(26.4 \%)$ & $2225(27.5 \%)$ & $2359(27.5 \%)$ & $2583(27.7 \%)$ & $<.0005$ \\
\hline Logistic EuroSCORE $>25$ & $2382(5.8 \%)$ & $378(5.1 \%)$ & $412(5.3 \%)$ & $511(6.3 \%)$ & $497(5.8 \%)$ & $584(6.3 \%)$ & .001 \\
\hline Aortic stenosis, n (row \%) & $24,829(63.7 \%)$ & $4104(62.4 \%)$ & $4408(63.2 \%)$ & $4951(63.4 \%)$ & $5373(64.0 \%)$ & $5993(65.1 \%)$ & $<.0005$ \\
\hline Biological valve, n (row \%) & $29,611(71.8 \%)$ & $4835(65.4 \%)$ & $5341(68.3 \%)$ & $5780(71.4 \%)$ & $6392(74.5 \%)$ & $7263(77.8 \%)$ & $<.0005$ \\
\hline Concomitant CABG, n (row \%) & $24,543(59.5 \%)$ & $4505(60.9 \%)$ & $4618(59.1 \%)$ & $4754(58.7 \%)$ & $5104(59.5 \%)$ & $5562(59.6 \%)$ & .245 \\
\hline Cardiogenic shock, n (row \%) & $358(0.9 \%)$ & $56(0.9 \%)$ & $71(1.0 \%)$ & $69(0.9 \%)$ & $95(1.2 \%)$ & $67(0.7 \%)$ & .419 \\
\hline
\end{tabular}

$S D$, Standard deviation; $B M I$, body mass index; $N Y H A$, New York Heart Association; $C A B G$, coronary artery bypass grafting.

\section{Independent Risk Factors for In-Hospital Mortality}

Multivariate logistic regression was applied to the data. The independent predictors of mortality are shown in Table E2. They include the following, in order of importance of categorical variables: redo surgery, cardiogenic shock, previous cardiac surgery, renal disease, nonelective surgery, concomitant CABG, NYHA class III/IV, EuroSCORE of 10 or more, nonsinus rhythm, female gender, impaired left ventricular function, peripheral vascular disease, and diabetes. Age was also a highly significant risk factor, analyzed as a continuous variable.

\section{Predictors of Out-of-Hospital Mortality}

The mean follow-up was 2.4 years and the longest follow-up was 5.2 years. Survival to census was $89 \%$.
Univariate associations are shown in Table E3. Survival was significantly impaired by age over 80 years, impaired left ventricular function, NYHA class III/IV, Canadian Cardiovascular Surgery class III/IV, renal disease, previous surgery, and additional grafts with AVR, pulmonary disease, diabetes, hypertension, and cardiogenic shock. The estimated survival of a patient with a biological valve was significantly lower than that of patients with a mechanical valve

Cox regression was applied to the data. The multivariate predictors of survival to census are shown in Table E4. Being male, having a low NYHA score, and absence of diabetes, renal disease, peripheral vascular disease, or cardiogenic shock were all predictors of survival. The hazard ratio for improved survival was 1.46 (95\% confidence interval

TABLE 2. The change of in-hospital mortality in different groups over time

\begin{tabular}{|c|c|c|c|c|c|c|c|}
\hline & \multirow[b]{2}{*}{ Total } & \multicolumn{5}{|c|}{ Financial year } & \multirow{2}{*}{$\begin{array}{l}P \text { value } \\
\text { for trend }\end{array}$} \\
\hline & & 2004-2005 & 2005-2006 & 2006-2007 & 2007-2008 & 2008-2009 & \\
\hline Octogenarians, n (\%) & $452(6.9 \%)$ & $84(8.4 \%)$ & $73(6.7 \%)$ & $95(7.3 \%)$ & $98(6.9 \%)$ & $102(6.0 \%)$ & .036 \\
\hline High risk, $\mathrm{n}(\%)$ & $1042(9.5 \%)$ & $196(10.8 \%)$ & $195(9.5 \%)$ & $210(9.5 \%)$ & $215(9.1 \%)$ & $226(8.8 \%)$ & .032 \\
\hline Stenosis, n (\%) & $972(3.9 \%)$ & $185(4.5 \%)$ & $176(4.0 \%)$ & $201(4.1 \%)$ & $205(3.8 \%)$ & $205(3.4 \%)$ & .07 \\
\hline Biological valve, n (\%) & $1333(4.5 \%)$ & $248(5.1 \%)$ & $246(4.6 \%)$ & $257(4.5 \%)$ & $289(4.5 \%)$ & $293(4.0 \%)$ & .008 \\
\hline Concomitant CABG, n (\%) & $910(5.5 \%)$ & $164(5.7 \%)$ & $191(6.0 \%)$ & $184(5.5 \%)$ & $191(5.5 \%)$ & $180(4.8 \%)$ & .053 \\
\hline Mortality (all), n (\%) & $1700(4.1 \%)$ & $326(4.4 \%)$ & $330(4.2 \%)$ & $342(4.2 \%)$ & $353(4.1 \%)$ & $349(3.7 \%)$ & .032 \\
\hline
\end{tabular}

$C A B G$, Coronary artery bypass grafting. 
TABLE 3. Patient characteristics and univariate association with inhospital mortality

\begin{tabular}{|c|c|c|c|}
\hline Risk factor & $\begin{array}{c}\text { Patients, } \\
\text { n (\%) }\end{array}$ & $\begin{array}{c}\text { In-hospital } \\
\text { mortality (\%) }\end{array}$ & $\begin{array}{c}P \\
\text { value }\end{array}$ \\
\hline \multicolumn{4}{|l|}{ Age groups } \\
\hline$<80 \mathrm{y}$ & $34,631(84.1 \%)$ & $3.6 \%$ & \multirow[t]{2}{*}{$<.0005$} \\
\hline$\geq 80 \mathrm{y}$ & $6,543(15.9 \%)$ & $6.9 \%$ & \\
\hline \multicolumn{4}{|l|}{ Female } \\
\hline No & $25,693(62.4 \%)$ & $3.7 \%$ & \multirow[t]{2}{*}{$<.0005$} \\
\hline Yes & $15,479(37.9 \%)$ & $4.9 \%$ & \\
\hline \multicolumn{4}{|l|}{ Impaired LV } \\
\hline No & $28,993(70.4 \%)$ & $2.9 \%$ & \multirow[t]{2}{*}{$<.0005$} \\
\hline Yes & $12,181(29.6 \%)$ & $7.0 \%$ & \\
\hline \multicolumn{4}{|l|}{ NYHA class III/IV } \\
\hline No & $22,274(54.1 \%)$ & $2.5 \%$ & \multirow[t]{2}{*}{$<.0005$} \\
\hline Yes & $18,900(45.9 \%)$ & $6.0 \%$ & \\
\hline \multicolumn{4}{|l|}{ CCS class III/IV } \\
\hline No & $34,544(83.9 \%)$ & $3.7 \%$ & \multirow[t]{2}{*}{$<.0005$} \\
\hline Yes & $6,630(16.1 \%)$ & $6.5 \%$ & \\
\hline \multicolumn{4}{|l|}{ Renal disease } \\
\hline No & $39,667(96.3 \%)$ & $3.8 \%$ & \multirow[t]{2}{*}{$<.0005$} \\
\hline Yes & $1,507(3.7 \%)$ & $12.4 \%$ & \\
\hline \multicolumn{4}{|l|}{$\begin{array}{l}\text { AVR hemodynamic } \\
\text { pathology }\end{array}$} \\
\hline Stenosis & $24,795(63.7 \%)$ & $3.9 \%$ & \multirow[t]{3}{*}{.007} \\
\hline Regurgitation & $5,799(14.9 \%)$ & $4.8 \%$ & \\
\hline Mixed & $8,319(21.9 \%)$ & $4.1 \%$ & \\
\hline \multicolumn{4}{|l|}{ Aortic valve implant type } \\
\hline Mechanical & $10,531(26.1 \%)$ & $3.1 \%$ & \multirow[t]{3}{*}{$<.0005$} \\
\hline Biological & $29,566(73.2 \%)$ & $4.5 \%$ & \\
\hline Homograft/autograft & $182(0.5 \%)$ & $7.7 \%$ & \\
\hline \multicolumn{4}{|l|}{ Concomitant CABG } \\
\hline No & $24,519(59.5 \%)$ & $3.2 \%$ & \multirow[t]{2}{*}{$<.0005$} \\
\hline Yes & $16,655(40.5 \%)$ & $5.5 \%$ & \\
\hline \multicolumn{4}{|l|}{ Previous surgery } \\
\hline No & $37,652(91.4 \%)$ & $3.5 \%$ & \multirow[t]{2}{*}{$<.0005$} \\
\hline Yes & $3,522(8.6 \%)$ & $10.4 \%$ & \\
\hline \multicolumn{4}{|l|}{ Pulmonary disease } \\
\hline No & $34,993(85.0 \%)$ & $3.9 \%$ & $<.0005$ \\
\hline Yes & $6,181(15.0 \%)$ & $5.6 \%$ & \\
\hline Diabetes & & & \\
\hline No & $34,648(84.2 \%)$ & $3.9 \%$ & $<.0005$ \\
\hline Yes & $6,526(15.8 \%)$ & $5.6 \%$ & \\
\hline Hypertension & & & \\
\hline No & $16,147(39.7 \%)$ & $3.6 \%$ & $<.0005$ \\
\hline Yes & $24,512(60.3 \%)$ & $4.5 \%$ & \\
\hline PVD & & & \\
\hline No & $36,643(89.5 \%)$ & $3.7 \%$ & $<.0005$ \\
\hline Yes & $4,288(10.5 \%)$ & $7.8 \%$ & \\
\hline Missing & & & \\
\hline Operative priority & & & \\
\hline Elective & $30,915(75.1 \%)$ & $2.9 \%$ & $<.0005$ \\
\hline Urgent/emergency & $10,259(24.9 \%)$ & $7.8 \%$ & \\
\hline Absence of sinus rhyth & & & \\
\hline No & $35,179(85.4 \%)$ & $3.5 \%$ & $<.0005$ \\
\hline Yes & $5,995(14.6 \%)$ & $7.9 \%$ & \\
\hline
\end{tabular}

TABLE 3. Continued

\begin{tabular}{lccc}
\hline \multicolumn{1}{c}{ Risk factor } & $\begin{array}{c}\text { Patients, } \\
\text { n (\%) }\end{array}$ & $\begin{array}{c}\text { In-hospital } \\
\text { mortality (\%) }\end{array}$ & $\begin{array}{c}\boldsymbol{P} \\
\text { value }\end{array}$ \\
\hline Missing & & & \\
$\quad$ Previous MIs & & & \\
$\quad$ None & $34,507(87.1 \%)$ & $3.5 \%$ & $<.0005$ \\
$\quad$ One & $4,330(10.9 \%)$ & $7.3 \%$ & \\
$\quad$ Two or more & $777(2.0 \%)$ & $11.7 \%$ & \\
BMI groups & & & \\
$\quad<35$ & $35,544(91.8 \%)$ & $4.1 \%$ & .847 \\
$\quad \geq 35$ & $3,195(8.2 \%)$ & $4.0 \%$ & \\
Cardiogenic shock & & & \\
$\quad$ No & $37,648(99.1 \%)$ & $3.9 \%$ & $<.0005$ \\
$\quad$ Yes & $356(0.9 \%)$ & $23.0 \%$ & \\
Missing & & & \\
\hline
\end{tabular}

$L V$, Left ventricle; $N Y H A$, New York Heart Association; $C C S$, Canadian Cardiovascular Society; $A V R$, aortic valve replacement; $C A B G$, coronary artery bypass grafting; $P V D$, peripheral vascular disease; $M I$, myocardial infarction; $B M I$, body mass index

[CI], 1.35-1.57) if the patient had a mechanical valve and $1.86(95 \% \mathrm{CI}, 1.73-1.99)$ if the patient was younger than 80 years of age.

\section{DISCUSSION \\ Statement of Principal Findings}

We have analyzed a large group of patients undergoing conventional aortic valve surgery. There has been a marked increase in the number of patients undergoing surgery each year, primarily owing to an increase in the number with aortic stenosis. There has been an increase in the mean age, the number of octogenarians, the number of high-risk patients, and the proportion receiving biological valves, particularly in younger patients. The mortality for octogenarians is $8.1 \%$ and for high-risk patients, $11.1 \%$, which should act as contemporary benchmarks against which to compare results of novel approaches to implantation of aortic valves and also to plan service provision in the future.

\section{Strengths and Weakness of Study}

This is a large study that is based on more than 41,227 patients undergoing AVR, with $6563(15.9 \%)$ being 80 or older and $11,043(26.8 \%)$ being "high risk." The data are collected prospectively in each unit, but units have not been routinely subjected to external validation. However, this database does have the confidence of clinicians and government and has a low incidence of missing data for most fields; as such, we believe it is fit for the purposes to which it has been applied.

In this study, only a small number of units have failed to submit data for single years, and because the missing data from centers are predominantly from the earlier years of the study, it is possible that some of the increase in numbers over time that we have seen is due to more complete data collection. However, after imputation to mitigate the effect of missing operations as described above, we have still seen 
TABLE 4. Changes in ratio of biological to mechanical valves in age groups $<55,55$ to 60,60 to 65,65 to $70,>70$ each year

\begin{tabular}{|c|c|c|c|c|c|c|}
\hline \multirow{2}{*}{$\begin{array}{c}\text { Financial } \\
\text { year }\end{array}$} & \multicolumn{5}{|c|}{ Age groups } & \multirow[b]{2}{*}{ Total } \\
\hline & $<55 \mathrm{y}$ & $55-60$ y & $60-65 y$ & $65-70 y$ & $>70 y$ & \\
\hline 2004-2005 & 0.18 & 0.23 & 0.37 & 0.62 & 0.87 & 0.65 \\
\hline $2005-2006$ & 0.21 & 0.26 & 0.42 & 0.66 & 0.90 & 0.68 \\
\hline 2006-2007 & 0.21 & 0.30 & 0.44 & 0.71 & 0.92 & 0.71 \\
\hline 2007-2008 & 0.22 & 0.34 & 0.50 & 0.75 & 0.94 & 0.74 \\
\hline 2008-2009 & 0.25 & 0.38 & 0.55 & 0.78 & 0.95 & 0.78 \\
\hline Total & 0.22 & 0.30 & 0.46 & 0.70 & 0.91 & 0.72 \\
\hline
\end{tabular}

a $26 \%$ increase in numbers. Conversely, there have been some changes in clinical practice over time that will have led to a potential "undercounting"; surgical atrial fibrillation procedures for concomitant atrial fibrillation were introduced during the study period and so patients with aortic stenosis and atrial fibrillation would have undergone isolated AVR at the beginning of the study period but may have undergone AVR plus atrial fibrillation ablation (and categorized as AVR plus other) during the later years. However, we think this number would be small and would not change our overall findings.

\section{Strength and Weaknesses Compared With Other Studies}

The largest accumulation of isolated AVRs is that in the Society of Thoracic Surgeons (STS) voluntary database. They have reported a total of 108,687 operations up to 2006 , with a mean age of 67 years, significantly younger than in our study. This database shows marked differences in patient characteristics to our analysis with higher incidences of female gender ( $42 \%$ vs $37.6 \%$ ), previous surgery $(16.5 \%$ vs $8.6 \%)$, and aortic stenosis $(76 \%$ vs $63.7 \%)$. The operative mortality in the STS database each year has run between 3\% and $4 \%$ for isolated AVR and $6 \%$ to $7 \%$ for combined AVR and CABG surgery, which are in line with the $3.2 \%$ and $5.5 \%$ mortalities for isolated and combined AVR seen in our study. ${ }^{5}$

TABLE 5. Comparison of patient undergoing isolated AVR and AVR plus CABG

\begin{tabular}{lccc}
\hline & AVR \& CABG & Isolated AVR & $\boldsymbol{P}$ value \\
\hline No. of patients & 16,684 & 24,543 & \\
Age (y), mean (SD) & $73.0(8.34)$ & $66.9(13.1)$ & $<.0005$ \\
Octogenarians, n (\%) & $3345(20.0 \%)$ & $3218(13.1 \%)$ & $<.0005$ \\
Female, n (\%) & $4945(29.6 \%)$ & $10,550(43.0 \%)$ & $<.0005$ \\
High risk, n (\%) & $5322(48.2 \%)$ & $5721(23.3 \%)$ & $<.0005$ \\
Stenosis, n (\%) & $10,968(69.5 \%)$ & $13,861(59.8 \%)$ & $<.0005$ \\
Previous operation, n (\%) & $800(4.8 \%)$ & $2730(11.1 \%)$ & $<.0005$ \\
Biological valve, n (\%) & $13,486(82.4 \%)$ & $16,125(67.0 \%)$ & $<.0005$ \\
Mechanical valve, n (\%) & $2833(17.3 \%)$ & $7704(32.0 \%)$ & $<.0005$ \\
Mortality, n (\%) & $910(5.5 \%)$ & $790(3.2 \%)$ & $<.0005$ \\
\hline
\end{tabular}

$A V R$, Aortic valve replacement; $C A B G$, coronary artery bypass grafting; $S D$, standard deviation.
We have seen marked changes in the use of biological valves over the period of study. The literature on the benefits of biological against mechanical valves has been comprehensively covered by the American College of Cardiology/American Heart Association guideline, which states that available randomized study data suggest slight advantages from mechanical valves, but also suggests that there has been a move in the United States toward more biological valve use because of potentially better freedom from structural deterioration in modern generation biological valves, perceived benefits of freedom from long-term anticoagulation, and increasing age of the population undergoing AVR. First-generation stented porcine valves had a relatively high incidence of structural deterioration (around $40 \%$ by 18 years), with higher incidences reported in younger patients. The more recent generation of valves has improved freedom from structural deterioration, but the incidence remains related to age at implantation., Between 1999 and 2002 the proportion of biological valves inserted in the aortic position for isolated valve replacement in the United States increased from 50\% to $65 \% .^{1}$ A previous report on national data from the United Kingdom contains an analysis of patients undergoing aortic valve surgery with and without coronary artery surgery in the years up to 2003 and shows the start of trends of increased age and increased use of biological valves that $w^{8}$ have also observed. In our study between 2004 and 2009 , the proportion of biological valves increased markedly over 5 years from $65.4 \%$ to $77.8 \%$. It is of interest that there has been an increase in the proportion of biological valves in all age groups, with the percentage of biological increasing from around $87 \%$ to nearly $95 \%$ in patients aged 70 or older and from $18 \%$ to $25 \%$ in those aged under 55 years. These changes will be important if the longevity of modern biological valves is not as good as expected. In addition, in the future, with increased uptake of selfmanagement, anticoagulation to more closely control the international normalized ratio, or even mechanical valves in low-risk patients that are maintained on clopidogrel and aspirin rather than warfarin, this trend may reverse.

We do not collect data on the type of biological valves (porcine, pericardial, and others), and it will be important to understand differences in structural deterioration between different types, but this is outside the scope of this study.

To help inform the current debate about high-risk patients with aortic valve disease and novel approaches to aortic valve implantation, we have looked particularly at elderly and high-risk patients, whom we have defined by using the EuroSCORE. There are many studies available analyzing patients purely on the cutoff of increased age, which is known to be a significant predictor of operative risk in patients undergoing AVR. ${ }^{9,10}$ Two large studies of results in elderly patients published in 1999 and 2000 showed 
in-hospital mortalities of around 7\% with 8 years' actuarial survival of $46 \%$ for isolated AVR and $10.1 \%$ for combined $\mathrm{AVR}$ and $\mathrm{CABG},{ }^{11,12}$ which are higher than those seen in our study. There are numerous single-center studies of AVRs in elderly patients using different age cutoffs, ${ }^{13-19}$ that in general show "satisfactory" in-hospital and longterm mortality, with good quality of life on follow-up. ${ }^{14,20}$ A recent single-institution study of 731 high-risk patients with a EuroSCORE of 7 or more showed that the logistic EuroSCORE significantly overpredicts in-hospital mortality and suggested a good 5-year survival of $72.4 \% .{ }^{6}$ There is always concern that there is "publication bias" from single-center studies, with only good outcomes finding their way into the literature, and as such an overall operative mortality of $4.5 \%$ with a mortality for high-risk patients of $9.8 \%$ from our large national database should be reassuring, and the results of novel approaches to treating aortic valve disease need to be seen in this context.

\section{Meaning of the Study}

This study demonstrates a $26 \%$ increase in the number of patients undergoing aortic valve surgery in the United Kingdom over a 5-year period, predominantly owing to an increase in patients with aortic stenosis. We have observed increases in the number of patients in all age groups, but this is most marked in the octogenarians, in whom the numbers have increased by $70 \%$. This implies either that aortic stenosis is becoming more common or that patients are more likely to be diagnosed, referred, and accepted for surgery. We suspect it is the latter, which presumably reflects improvements throughout primary, secondary, and tertiary care in the United Kingdom. The time period of our study shortly follows the introduction of a National Service Framework for coronary artery disease, which gave guidance about processes, standards, and targets for treating patients with ischemic heart disease. It is likely that this initiative has improved overall cardiology services. Symptomatic aortic stenosis has a high mortality if left untreated; thus the increased numbers of patients coming to surgery should be reflected in increased life expectancy and improved quality of life for the population.

The increased use of biological valves in younger age groups is not based on evidence from randomized studies. This strategy has been challenged ${ }^{21}$ and it will be important to monitor the outcomes of these patients closely. Of note, we found that on multivariate analysis there was an increased odds of out-of-hospital mortality with a biological valve. This should be interpreted with caution, but several other authors have also reported this outcome in similar such cohort studies. ${ }^{22-25}$ The reasons may include preoperative variables that select more frail patients for biological valves that are not captured by the variables that we collected. Alternatively, there may be an adverse association that requires further investigation.
There has also been a doubling in the number of high-risk patients undergoing surgery. These patients have a high mortality of $8.8 \%$, but it should be noted that there has been a significant trend of decreasing operative mortality in these high-risk patients over time. Newer techniques of aortic valve implantation through either transarterial or cardiac transapical routes are now being introduced. These techniques also have a significant mortality and morbidity and uncertain mid to longer outcomes, ${ }^{26,27}$ but the data provided in this study will allow results of these novel techniques to be seen against contemporary outcomes of conventional surgery.

\section{Unanswered Questions and Future Research}

We have seen a marked increase in the number of patients undergoing AVR in the United Kingdom, but we do not know whether this is due to an increasing incidence of aortic stenosis in a population of increased age or whether it simply reflects unmasking of unmet need by better health care services. It is likely that there are marked variations in the number of operations per million population per year between different regions, and more detailed investigation of geographic variation may be interesting. We have shown marked increases in biological valve usages, particularly in younger patients. The longer-term outcomes of the latest valves in this population are not certain and will need to be monitored closely. We have shown the in-hospital mortality for highrisk patients undergoing conventional AVR, which will be informative as a contemporary benchmark for novel approaches, but it would be useful to describe the midterm and longer-term outcomes of the high-risk patients in more detail along with the clinical factors indicative of poor outcomes in this group.

This study has been performed on behalf of the Society for Cardiothoracic Surgery in Great Britain and Ireland. We thank all the surgeons in the United Kingdom whose data have contributed to the database. We acknowledge the extensive contributions of the database managers in each organization, without whose work this study would not be possible. Finally, we thank the Healthcare Quality Improvement Partnership (and previously the National Clinical Audit Support Programme) for financial support for collecting and collating data for this audit and David Cunningham and his coworkers at CCAD for their help in supplying the data for this analysis.

\section{References}

1. Bonow RO, Carabello BA, Kanu C, De Leon AC, Faxon DP, Freed MD, et al. ACC/AHA 2006 guidelines for the management of patients with valvular heart disease: a report of the American College of Cardiology/American Heart Association Task Force on Practice Guidelines. Circulation. 2006;114:e84-231.

2. Grube E, Schler G, Buellerfeld L, Geckens U, Linke A, Wenaweser P, et al. Percutaneous aortic valve replacement for severe aortic stenosis in high risk patients using the second- and current third-generation self-expanding CoreValve prosthesis: device success and 30-day clinical outcome. J Am Coll Cardiol. 2007; 50:69-76.

3. Svensson LG, Dewey T, Kapadia S, Roselli EE, Stewart A, Williams M, et al. United States feasibility study of transcatheter insertion of stented aortic valve by the left ventricular apex. Ann Thorac Surg. 2008;86:46-54. 
4. Roques F, Michel P, Goldstone AR, Nashef SAM. The logistic EuroSCORE. Eur Heart J. 2003;24:1-2.

5. Brown JM, O'Brien SM, Wu C, Sikora JAH, Griffith BP, Gammie JS. Isolated aortic valve replacement in North America comprising 108,687 patients in 10 years: changes in risks, valve types and outcomes in the Society of Thoracic Surgeons National Database. J Thorac Cardiovasc Surg. 2009;137:82-90.

6. Pelletier LC, Carrier M, Leclerk Y, Dyrda I. The Carpentier-Edwards pericardial bioprosthesis: clinical experience with 600 patients. Ann Thorac Surg. 1995;60: S297-302.

7. Banbury MK, Cosgrove DM, White JA, Blackstone EH, Frater RW, Okies JE Age and valve size effect on the long-term durability of the CarpentierEdwards aortic pericardial bioprosthesis. Ann Thorac Surg. 2001;72:753-7.

8. Bridgewater B, Kinsman R, Walton P, Keogh B. Sixth National Adult Cardiac Surgical database report 2008. ISBN 1-903968-23-2. Dendrite Clinical Systems Ltd; Oxfordshire (UK).

9. Kuduvalli M, Grayson AD, Au J, Grotte G, Bridgewater B, Fabri BM. A multicentre additive and logistic risk model for in-hospital mortality following aortic valve replacement. Eur J Cardiothorac Surg. 2007;31607-13.

10. Florath I, Rosendahl UP, Mortasawi A, Bauer SF, Dalladaku F, Ennker IC, et al. Current determinants of operative mortality of 1400 patients requiring aortic valve replacement. Ann Thorac Surg. 2003;76:75-83.

11. Asimakopoulos G, Edwards MB, Taylor KM. Aortic valve replacement in patients 80 years of age and older: survival and cause of death based on 1100 cases: collective results from the UK Heart Valve Registry. Circulation. 1997;96: 3403-8.

12. Alexander KP, Anstrom KJ, Muhlbaier LH, Grosswald RD, Smith PK, Jones RH, et al. Outcomes of cardiac surgery in patients age $>$ or $=80$ years: results from the National Cardiovascular Network. J Am Coll Cardiol. 2000;35:731-8.

13. Kolh P, Kerzmann A, Honore C, Comte L, Limet R. Aortic valve surgery in octogenarians: predictive factors for operative and long term results. Eur J Cardiothoracic Surg. 2007;31:600-6.

14. Kolh P, Lahaye L, Gerard P, Limet R. Aortic valve replacement in the octogenarians: peri-operative outcome and clinical follow-up. Eur J Cardiothorac Surg. 1999;16:68-73.

15. Melby SJ, Zierer A, Kaiser SP, Guthrie TJ, Keune JD, Schuessler RB, et al. Aortic valve replacement in octogenarians: risk factors for early and late mortality. Ann Thorac Surg. 2007;83:1651-6.

16. Roberts WC, Ko JM, Garner WL, Filardo G, Henry AC, Hebeler RF, et al. Valve structure and survival in octogenarians having aortic valve replacement for aortic stenosis ( $H$ - regurgitation) with versus without coronary artery bypass grafting at a single US medical centre (1993 to 2005). Am J Cardiol. 2007;100: 489-95.

17. Tseng EE, Lee CA, Cameron DE, Stuart RS, Greene PS, Sussman MS, et al. Aortic valve replacement in the elderly: risk factors and long-term results. Ann Surg. 1997;225:793-804

18. Elayada MA, Hall RJ, Reul RM, Alonzo DM, Gillett N, Reul GJJ, et al. Aortic valve replacement in patients 80 years and older. Operative risks and longterm results. Circulation. 1993;88:11-6.

19. Collart F, Feier H, Kerbaul F, Mouly-Bndini A, Riberi A, Mesana TG, et al. Valvular surgery in octogenarians: operative risk factors, evaluation of EuroSCORE and long-term results. Eur J Cardiothorac Surg. 2005;27:276-80.

20. Sundt TM, Bailey MS, Moon MR, Mendeloff EN, Huddleston CB, Pasque MK, et al. Quality of life after aortic valve replacement at the age of $>80$ years. Circulation. 2000;102(19 suppl 3):11170-4.

21. Brown ML, Schaff HV, Lahr BD, Mullany CJ, Sundt TM, Dearani JA, et al. Aortic valve replacement in patients aged 50 to 70 years: improved outcome with mechanical versus biologic prostheses. J Thorac Cardiovasc Surg. 2008; 135:878-84.

22. Jamieson WR, Ye J, Higgins J, Cheung A, Fradet GJ, Skarsgard P, et al. Effect of prosthesis-patient mismatch on long-term survival with aortic valve replacement: assessment to 15 years. Ann Thorac Surg. 2010;89:51-8.

23. Brown ML, Schaff HV, Lahr BD, Mullany CJ, Sundt TM, Dearani JA, et al. Aortic valve replacement in patients aged 50 to 70 years: improved outcome with mechanical versus biologic prostheses. J Thorac Cardiovasc Surg. 2008; 135:878-84.

24. Vicchio M, Della Corte A, De Santo LS, De Feo M, Caianiello G, Scardone M, et al. Tissue versus mechanical prostheses: quality of life in octogenarians. Ann Thorac Surg. 2008;85:1290-5.

25. de Vincentiis C, Kunkl AB, Trimarchi S, Gagliardotto P, Frigiola A, Menicanti L, et al. Aortic valve replacement in octogenarians: is biologic valve the unique solution? Ann Thorac Surg. 2008;85:1296-301.

26. Yan TD, Cao C, Martens-Nielsen J, Padang R, Ng M, Vallely MP, et al. Transcatheter aortic valve implantation for high-risk patients with severe aortic stenosis: a systematic review. J Thorac Cardiovasc Surg. 2010;139: 1519-28.

27. Ye J, Cheung A, Lichtenstein SV, Nietlispach F, Albugami S, Masson JB, et al. Transapical transcatheter aortic valve implantation: follow-up to 3 years. J Thorac Cardiovasc Surg. 2010;139:1107-13. 
TABLE E1. Other outcome measures

\begin{tabular}{|c|c|c|c|c|c|c|c|}
\hline & \multicolumn{6}{|c|}{ Financial year } & \multirow{2}{*}{$\begin{array}{c}P \text { value } \\
\text { for trend }\end{array}$} \\
\hline & Total & 2004-2005 & 2005-2006 & 2006-2007 & 2007-2008 & 2008-2009 & \\
\hline No. of patients & 41,227 & 7,396 & 7,816 & 8,097 & 8,585 & 9,333 & \\
\hline $\begin{array}{l}\text { Permanent CVA, n (rate \%) } \\
\text { all patients }\end{array}$ & $416(1.2 \%)$ & $77(1.4 \%)$ & $70(1.1 \%)$ & $82(1.2 \%)$ & $101(1.3 \%)$ & $86(1.0 \%)$ & .183 \\
\hline $\begin{array}{l}\text { Permanent CVA in patients } \\
\text { with AVR only, } n \text { (rate \%) }\end{array}$ & $201(1.0 \%)$ & $29(0.8 \%)$ & $33(0.9 \%)$ & $39(0.9 \%)$ & $54(1.2 \%)$ & $46(0.9 \%)$ & .665 \\
\hline $\begin{array}{l}\text { Postoperative dialysis, } \\
\text { n (rate \%) all patients }\end{array}$ & $1516(4.5 \%)$ & $213(3.8 \%)$ & $260(4.2 \%)$ & $298(4.3 \%)$ & $426(5.7 \%)$ & $319(4.2 \%)$ & $<.0005$ \\
\hline $\begin{array}{l}\text { Postoperative dialysis in } \\
\text { patients with AVR only, } \\
\text { n (rate \%) }\end{array}$ & $721(3.6 \%)$ & $108(3.1 \%)$ & $108(1.0 \%)$ & $145(3.6 \%)$ & $207(4.7 \%)$ & $153(3.3 \%)$ & .001 \\
\hline $\begin{array}{l}\text { In-hospital reoperation, } \\
\text { n (rate \%) }\end{array}$ & $2941(8.2 \%)$ & $523(8.4 \%)$ & $544(8.2 \%)$ & $581(8.5 \%)$ & $607(8.2 \%)$ & $686(8.0 \%)$ & .777 \\
\hline $\begin{array}{l}\text { Reoperation for bleeding, } \\
\text { n (rate } \%)\end{array}$ & $2342(6.6 \%)$ & $423(6.8 \%)$ & $425(6.4 \%)$ & $454(6.6 \%)$ & $476 \%(6.4 \%)$ & $564(6.5 \%)$ & .885 \\
\hline
\end{tabular}

TABLE E2. Independent predictors for in-hospital mortality

\begin{tabular}{|c|c|c|c|c|c|}
\hline \multirow[b]{2}{*}{ NYHA class III/IV } & \multirow{2}{*}{$\frac{\text { B-coefficient }}{0.501}$} & \multirow{2}{*}{$\frac{\text { Odds ratio }(\exp B)}{1.65}$} & \multicolumn{2}{|c|}{$95.0 \%$ CI } & \multirow{2}{*}{$\frac{P \text { value }}{<.0005}$} \\
\hline & & & 1.48 & 1.84 & \\
\hline Concomitant CABG & 0.524 & 1.68 & 1.51 & 1.88 & $<.0005$ \\
\hline Previous cardiac surgery & 0.950 & 2.58 & 2.24 & 2.98 & $<.0005$ \\
\hline Diabetes & 0.165 & 1.18 & 1.04 & 1.34 & .01 \\
\hline Peripheral vascular disease & 0.228 & 1.26 & 1.09 & 1.44 & .002 \\
\hline Nonelective surgery & 0.563 & 1.76 & 1.58 & 1.95 & $<.0005$ \\
\hline Absence of sinus rhythm & 0.441 & 1.55 & 1.38 & 1.75 & $<.0005$ \\
\hline Age (decade) & 0.257 & 1.29 & 1.20 & 1.40 & $<.0005$ \\
\hline Impaired LV & 0.361 & 1.43 & 1.28 & 1.60 & $<.0005$ \\
\hline Cardiogenic shock & 0.952 & 2.59 & 1.94 & 3.45 & $<.0005$ \\
\hline Renal disease & 0.804 & 2.24 & 1.86 & 1.04 & $<.0005$ \\
\hline Female & 0.361 & 1.44 & 1.29 & 1.60 & $<.0005$ \\
\hline EuroSCORE $\geq 10$ & 0.476 & 1.61 & 1.40 & 1.86 & $<.0005$ \\
\hline
\end{tabular}

$C I$, Confidence interval; $N Y H A$, New York Heart Association; $C A B G$, coronary artery bypass grafting; $L V$, left ventricle. 
TABLE E3. Univariate association with survival

\begin{tabular}{|c|c|c|c|}
\hline Risk factor & Patients & $\begin{array}{l}\text { Estimated survival } \\
\text { in days (SE) }\end{array}$ & $P$ value \\
\hline \multicolumn{4}{|l|}{ Age groups } \\
\hline$<80 \mathrm{y}$ & 27,017 & $1,686(3.64)$ & \multirow[t]{2}{*}{$<.0005$} \\
\hline$\geq 80 \mathrm{y}$ & 5,182 & $1,450(11.2)$ & \\
\hline \multicolumn{4}{|l|}{ Female } \\
\hline No & 20,121 & $1,652(4.49)$ & \multirow[t]{2}{*}{.408} \\
\hline Yes & 12,078 & $1,646(5.87)$ & \\
\hline \multicolumn{4}{|l|}{ Impaired LV } \\
\hline No & 22,155 & $1,700(3.91)$ & \multirow[t]{2}{*}{$<.0005$} \\
\hline Yes & 10,044 & $1,537(7.35)$ & \\
\hline \multicolumn{4}{|l|}{ NYHA class III/IV } \\
\hline No & 17,385 & $1,708(4.38)$ & \multirow[t]{2}{*}{$<.0005$} \\
\hline Yes & 14,814 & $1,583(5.73)$ & \\
\hline \multicolumn{4}{|l|}{ CCS class III/IV } \\
\hline No & 27,159 & $1,664(3.800$ & \multirow[t]{2}{*}{$<.0005$} \\
\hline Yes & 5,040 & $1,576(9.91)$ & \\
\hline \multicolumn{4}{|l|}{ Renal disease } \\
\hline No & 31,028 & $1,665(3.54)$ & \multirow[t]{2}{*}{$<.0005$} \\
\hline Yes & 1,171 & $1,249(25.4)$ & \\
\hline \multicolumn{4}{|c|}{ AVR hemodynamic pathology } \\
\hline Stenosis & 2,0415 & $1,649(4.50)$ & \multirow[t]{3}{*}{.876} \\
\hline Regurgitation & 4,716 & $1,655(9.20)$ & \\
\hline Mixed & 5,975 & $1,649(8.26)$ & \\
\hline \multicolumn{4}{|c|}{ Aortic valve implant type } \\
\hline Nonbiological & 8,886 & $1,735(5.59)$ & \multirow[t]{2}{*}{$<.0005$} \\
\hline Biological & 2,3313 & $1,614(4.46)$ & \\
\hline \multicolumn{4}{|l|}{ Concomitant CABG } \\
\hline No & 19,120 & $1,695(4.27)$ & \multirow[t]{2}{*}{$<.0005$} \\
\hline Yes & 13079 & $1583(6.13)$ & \\
\hline \multicolumn{4}{|l|}{ Previous surgery } \\
\hline No & 29,519 & $1,664(3.63)$ & \\
\hline Yes & 2,680 & $1,496(14.9)$ & \\
\hline \multicolumn{4}{|l|}{ Pulmonary disease } \\
\hline No & 2,7236 & $1,666(3.77)$ & $<.0005$ \\
\hline Yes & 4,963 & $1,560(10.2)$ & \\
\hline Diabetes & & & \\
\hline No & 27,094 & $1,666(3.77)$ & $<.0005$ \\
\hline Yes & 5,105 & $1,558(10.3)$ & \\
\hline Hypertension & & & \\
\hline No & 12,637 & $1,691(5.24)$ & $<.0005$ \\
\hline Yes & 19,180 & $1,623(4.84)$ & \\
\hline PVD & & & \\
\hline No & 29,049 & $1,670(3.62)$ & $<.0005$ \\
\hline Yes & 3,150 & $1,456(14.1)$ & \\
\hline Operative priority & & & \\
\hline Elective & 23,793 & $1,695(3.82)$ & $<.0005$ \\
\hline Urgent/emergency & 8,406 & $1,521(8.15)$ & \\
\hline Absence of sinus rhy & & & \\
\hline No & 27,428 & $1,681(3.66)$ & $<.0005$ \\
\hline Yes & 4,771 & $1,467(11.3)$ & \\
\hline Previous MIs & & & \\
\hline None & 2,7145 & $1,673(3.74)$ & \\
\hline One & 3,320 & $1,539(12.9)$ & \\
\hline Two or more & 629 & $1,386(32.7)$ & \\
\hline
\end{tabular}

$$
\text { Yes }
$$$$
17,385
$$$$
27,159
$$$$
31,028
$$$$
\text { ogy }
$$$$
\text { Stenosis }
$$

2,0415

4,716

$1,655(9.20)$

$1,735(5.59)$

$1,695(4.27)$

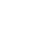

.
TABLE E3. Continued

\begin{tabular}{|c|c|c|c|}
\hline Risk factor & Patients & $\begin{array}{l}\text { Estimated survival } \\
\text { in days (SE) }\end{array}$ & $P$ value \\
\hline \multicolumn{4}{|l|}{ BMI groups } \\
\hline$<35$ & 29,689 & $1,648(3.71)$ & .165 \\
\hline$\geq 35$ & 2510 & $1664(12.9)$ & \\
\hline \multicolumn{4}{|l|}{ Cardiogenic shock } \\
\hline No & 31,918 & $1,653(3.56)$ & $<.0005$ \\
\hline Yes & 281 & 1,217 (53.6) & \\
\hline
\end{tabular}

$S E$, Standard error; $L V$, left ventricle; $N Y H A$, New York Heart Association; $C C S, \mathrm{Ca}-$ nadian Cardiovascular Society; $A V R$, aortic valve replacement; $C A B G$, coronary artery bypass grafting; $P V D$, peripheral vascular disease; $M I$, myocardial infarction; $B M I$, body mass index. 
TABLE E4. Independent predictors for out-of-hospital mortality

\begin{tabular}{|c|c|c|c|c|}
\hline & B coefficient & Odds ratio exp (B) & $95 \% \mathrm{CI}$ & $P$ value \\
\hline Female gender & 0.083 & 1.086 & $1.021-1.156$ & .009 \\
\hline Impaired LV & 0.319 & 1.376 & $1.293-1.464$ & $<.0005$ \\
\hline NYHA class III/IV & 0.250 & 1.283 & $1.205-1.367$ & $<.0005$ \\
\hline CCS class III/IV & -0.034 & .966 & $.893-1.045$ & .39 \\
\hline Diabetes & 0.247 & 1.280 & $1.188-1.378$ & $<.0005$ \\
\hline Pulmonary disease & 0.225 & 1.253 & $1.164-1.348$ & $<.0005$ \\
\hline Renal disease & 0.805 & 2.236 & $2.012-2.486$ & $<.0005$ \\
\hline Neurological dysfunction & 0.104 & 1.110 & $.943-1.305$ & .21 \\
\hline Extracardiac arteriopathy & 0.357 & 1.430 & $1.318-1.551$ & $<.0005$ \\
\hline Absence of sinus rhythm & 0.505 & 1.656 & $1.545-1.775$ & $<.0005$ \\
\hline Cardiogenic shock & 0.505 & 1.656 & $1.352-2.029$ & $<.0005$ \\
\hline Nonelective surgery & 0.349 & 1.418 & $1.331-1.511$ & $<.0005$ \\
\hline Redo surgery & 0.567 & 1.763 & $1.612-1.928$ & $<.0005$ \\
\hline BMI 35 or more & 0.009 & 1.009 & $.897-1.134$ & .88 \\
\hline Additional CABG surgery & 0.318 & 1.374 & $1.289-1.464$ & $<.0005$ \\
\hline Biological valve & 0.378 & 1.460 & $1.351-1.578$ & $<.0005$ \\
\hline$>80 \mathrm{y}$ & 0.619 & 1.856 & $1.732-1.990$ & $<.0005$ \\
\hline EuroSCORE $>10$ & 0.476 & 1.609 & $1.483-1.746$ & $<.0005$ \\
\hline
\end{tabular}

$C I$, Confidence interval; $L V$, left ventricle; $N Y H A$, New York Heart Association; $C C S$, Canadian Cardiovascular Society; $B M I$, body mass index; $C A B G$, coronary artery bypass grafting. 